\title{
EVALUATION OF ANTIULCEROGENIC ACTIVITY OF METHANOL EXTRACTS OF BRASSICA OLERACEA VAR. CAPITATA RUBRA ON ALBINO RAT GASTRIC ULCERATION
}

\author{
SUDHARAMESHWARI K*, AYSHWARYA M \\ Department of PG Biochemistry, V. V. Vanniaperumal College for Women, Virudhunagar, Tamil Nadu, India. *Email: sudhavvvc@gmail.com \\ Received: 18 November 2016, Revised and Accepted: 05 December 2016
}

ABSTRACT

Objective: To investigate the antiulcerogenic activity of methanolic extract of Brassica var. capitata rubra in albino rats.

Methods: To evaluate the antiulcer activity by pyloric ligation models experimentally induced gastric ulcer by ranitidine (10 mg/kg) subcutaneously. The parameters taken to assess antiulcer activity were free acidity, total acidity, volume of gastric juice, $\mathrm{PH}$, ulcer score, and ulcer index.

Results: The methanolic extract of Brassica oleracea var. capitata rubra in the dose of $0.50 \mathrm{mg} / \mathrm{kg}$ produced significant antiulcer activity. The control animals had ulcers and hemorrhagic streaks, whereas in animals administered with extracts of B. oleracea there was a significant reduction in ulcer index $(\mathrm{p}<0.05)$

Conclusion: This study concluded that methanol extract of B. oleracea var. capitata has healing property of gastric ulcers in albino rats.

Keywords: Brassica, Methanol extract, Antiulcer activity, Pyloric ligation model.

(C) 2017 The Authors. Published by Innovare Academic Sciences Pvt Ltd. This is an open access article under the CC BY license (http://creativecommons. org/licenses/by/4. 0/) DOI: http://dx.doi.org/10.22159/ajpcr.2017.v10i3.16217

\section{INTRODUCTION}

A peptic ulcer is the most common gastrointestinal disorder in clinical practice. Prolonged use of synthetic antiulcer drugs leads to adverse drug reactions. Hence, search for new antiulcer agents that retain therapeutic efficacy and are devoid of drug reactions lead to the usage of natural medicine [1]. Brassica oleracea belongs to Brassicaceae or Cruciferae family comprised approximately 3500 described species apportioned among 350 genera including cauliflower, broccoli, kohlrabi, kale, cabbage, and Brussels sprouts.

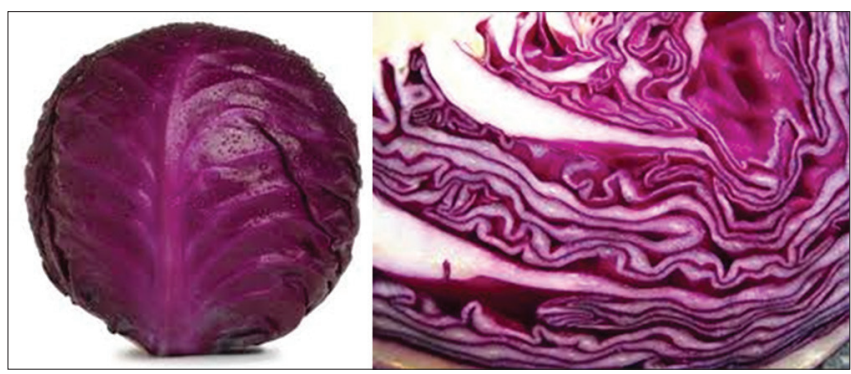

Red cabbage is a rich source of phenolic compounds, with anthocyanins being predominant over other flavonoids [2,3]. The highest stability and strongest antioxidant properties in red cabbage extract were assigned to anthocyanins [4]. Numerous studies have highlighted the potential importance of brassica vegetables as a source of antibacterial [5-7] and antioxidant substance [8-10]. Due to its antioxidant, anti-inflammatory and antibacterial properties, cabbage has widespread use in traditional medicine, in alleviation of symptoms associated with gastrointestinal diseases (gastritis, peptic and duodenal ulcers, and irritable bowel syndrome) as well as in the treatment of minor cuts and wounds and mastitis [11].

In our study, methanol extract of $B$. oleracea showed significant results regarding photochemical [12], antimicrobial [13], and antioxidant studies [14] and pharmacologic studies namely anti-inflammatory and antipyretic activity [15]. Hence, in this study, pharmacologic activity of antiulcer has been investigated in the methanol extract of Brassica plant.

\section{METHODS}

This project was conducted in the Department of PG Biochemistry at V.V. Vanniaperumal College for Women, Virudhunagar, Tamil Nadu, India. The preliminary work (extraction) was conducted in V.V. Vanniaperumal College for Women, Virudhunagar, Tamil Nadu, India. The pharmacologic activity of drug on rat study was conducted in the Sankaralingam Bhuvaneswari College of Pharmacy, Anaikuttum, Tamil Nadu, India.

\section{Vegetable collection}

Red cabbage (B. oleracea var. capitata rubra) was collected from local markets of Virudhunagar, Tamil Nadu, India, and was authenticated by Dr. B. Karunai Selvi, Assistant Professor, Department of Botany, V. V. Vanniaperumal College for Women, Virudhunagar, Tamil Nadu, India. The vegetable was washed thoroughly under running tap water to remove dirt and then shade dried at room temperature for a week. They were ground into fine particles after drying and kept in closed container.

\section{Extraction and sample preparation}

About $10 \mathrm{~g}$ of ground sample of B. oleracea var. capitata rubra was weighed and homogenized with $100 \mathrm{ml}$ of methanol. The crude preparation was left for 72 hrs in shaker at room temperature. The extract obtained by cold extraction was then concentrated by evaporating the solvent at room temperature.

\section{Animal model}

Wistar rats of either sex weighing between 130 and $170 \mathrm{~g}$ were procured from animal house of Sankaralingam Bhuvaneswari College of Pharmacy (Regd. No. 622/02/C/CPCSEA) used for this study. They were maintained under standard conditions $\left(28 \pm 2^{\circ} \mathrm{C} ; 55-60 \%\right.$ relative humidity) and fed a standard diet for rats and given water ad libitum. 


\section{Antiulcer activity}

The animals were starved overnight and the first group of animals was given saline orally - $5 \mathrm{ml} / \mathrm{kg}$ (control), second was injected ranitidine $10 \mathrm{mg} / \mathrm{kg}$ subcutaneously and the next two groups were given different concentrations of extract $\left(\mathrm{T}_{1}-0.25 \mathrm{mg} / \mathrm{kg}\right.$ and $\left.\mathrm{T}_{2}-0.50 \mathrm{mg} / \mathrm{kg}\right)$ orally. The rat was anesthetized with anesthetic ether. After 15 minutes of injection, pyloric ligation was performed. The rat was secured on the operating table. An incision of $1 \mathrm{~cm}$ length is given in the abdomen just below the sternum. The stomach was exposed. Passed a thread around the pyloric sphincter and applied a tight knot. While putting the knot care should be taken so that no blood vessel is tied along the knot. The abdomen wall was closed by putting the sutures. Cleaned the skin from any blood spots and bleeding. The collodion was applied over the wound. The rat was kept in the separate cage and allowed to recover. After $4 \mathrm{hrs}$ of pyloric ligation, the animals are sacrificed by decapitation. Opened the abdomen and tied the esophageal end (cardiac end) of the stomach. Cut and removed the entire stomach from the body of the animal. Given a small cut to the pyloric region just above, the knot and collected the contents of the stomach in a graduated centrifuge tube. Opened the stomach along the curvature and washed it slowly under the running tap water. Put it on the slide glass and observed under $10 \times$ magnification for ulcers. The ulcers are scored as below.

$0=$ Normal colored stomach

$0.5=$ Red coloration

$1=$ Spot ulcers

$1.5=$ Hemorrhagic streaks

$2=$ Ulcers $\geq 3$ but $\leq 5$

$3=$ Ulcers $>5$.

Mean ulcer score for each animal was expressed as ulcer index. Gastric content was centrifuged at $1000 \mathrm{rpm}$ for 10 minutes. $\mathrm{pH}$ of this solution was noted with the help of $\mathrm{pH}$ meter. The solution was titrated against $0.01 \mathrm{~N}$ sodium hydroxide using Topfer's reagent as indicator. (It is dimethyl amino-azo-benzene with phenolphthalein and used for detection and estimation of hydrochloric acid and total acidity in gastric fluids). The end point is the appearance of orange color. The volume of sodium hydroxide was noted which corresponds to the free acidity. The solution was titrated further, till it regained pink color. The total volume of sodium hydroxide which corresponds to the total acidity was noted [16].

Acidity $(\mathrm{mEq} / 100 \mathrm{~g})$ can be expressed as:

Acidity=Volume of sodium hydroxide $\times$ normality $\times 100 / 0.1$.

Statistical analysis was performed by one-way ANOVA followed by student's test using SPSS software.

\section{RESULTS AND DISCUSSION}

The plant B. oleracea var. capitata rubra was collected from local markets of Virudhunagar, Tamil Nadu. The material was dried under shade and then powdered. The dried powders of $B$. oleracea were extracted with methanol solvents using cold extraction. The extracts were allowed to evaporate to dryness.
We chose methanol extract for further pharmacological study in antiulcer activity. The methanolic extract of B. oleracea var. capitata rubra in the dose of $0.50 \mathrm{mg} / \mathrm{kg}$ produced significant antiulcer activity. The control animals had ulcers and hemorrhagic streaks, whereas in animals administered with extracts of $B$. oleracea there was a significant reduction in ulcer index $(\mathrm{p}<0.05)$. The results of antiulcer activity are tabulated in Table 1 and diagrammatically represented in Plate 1.

The methanol extract of the $B$. oleracea has significantly shown reduced values of lesion index as compared to control group suggesting its potent cytoprotective effect. It has been proposed that in pyloric ligation, the digestive effect of accumulated gastric juice and interference of gastric blood circulation are responsible for induction of ulceration [17]. The antiulcer activity of methanol extract of B. oleracea in pylorus ligation model was evident from its significant reduction in gastric volume, total acidity, free acidity, ulcer index, and increase in $\mathrm{pH}$ of gastric juice. It is generally accepted that gastric ulcers result from an imbalance between aggressive factors and the maintenance of the mucosal integrity through endogenous defense mechanisms [18]. The excess gastric formation of prostaglandin (PG) includes both increases in mucosal resistance as well as a decrease in aggressive factors, mainly acid, and pepsin [19]. Acute gastric ulcers were induced in rats by the oral administration of acetylsalicylic acid. The gastroprotective potential of aqueous extract $(0.250,0.500$, and $1.0 \mathrm{mg} / \mathrm{kg}$ body weight) was compared with omeprazole $(20 \mathrm{mg} / \mathrm{kg}$ body weight). The stomach analysis indicated the gastric damage. The gastroprotective activities were evidenced by its significant inhibition in the formation of ulcers induced by chemical agent with a maximum of $99.44 \%$ curation in acetylsalicylic acid-induced ulcer [20]. The effect of methanolic, chloroform and diethyl ether extracts of Mimosa pudica were investigated in rats to evaluate the antiulcer activity using three models, i.e., aspirin, alcohol, and pyloric ligation models experimentally induced gastric ulcer. The parameter assessed was gastric volume, $\mathrm{pH}$, free acidity, total acidity, and ulcer index. The results indicated that there is a significant decrease in all the above-mentioned parameter in alcohol extract with respect to control [21]. The patients who utilized the fresh cabbage juice obtained a healing action for gastric disorders, particularly for the peptic ulcer, presenting healing effects of the lesion [22]. The preliminary phytochemical studies revealed the presence of flavonoids in methanolic extract of B. oleracea. A possible mechanism of antiulcer action of B. oleracea may be due to its flavonoids content. Flavonoids may be recognized as active compounds against gastric lesions [23]. Our results are coincides with this.

For the therapeutic strategies of gastroduodenal ulcer disease, it is an important to find antioxidant compounds that are able to inhibit the gastric acid secretion, boost the mucosal defense mechanisms by increasing mucosal production, and stabilizing the surface epithelial cells [24]. Natural products were considered as a rich source of compounds for drug discovery [25]. Therefore, by scavenging free radicals, antioxidants from plant sources may play an important role in gastric ulcer therapy [26]. In accordance with this report, methanolic extract showed the highest scavenging capacity for 2,2-diphenyl1-picrylhydrazyl radical, superoxide radical scavenging activity recorded in our study [14]. Gastric acid oversecretion is one of the

Table 1: Antiulcer activity by pyloric ligation method

\begin{tabular}{|c|c|c|c|c|c|c|}
\hline \multirow[t]{2}{*}{ Drug and dose } & \multicolumn{2}{|c|}{ Acidity (mEq/l) } & \multirow[t]{2}{*}{ Volume of gastric juice $(\mathrm{ml})$} & \multirow[t]{2}{*}{ pH of gastric juice } & \multirow[t]{2}{*}{ Ulcer score } & \multirow[t]{2}{*}{ Ulcer index (\%) } \\
\hline & Free acidity & Total acidity & & & & \\
\hline $\begin{array}{l}\text { Control } \\
\text { Normal saline } \\
5 \mathrm{ml} / \mathrm{kg}\end{array}$ & $25.5 \pm 1.0$ & $70.75 \pm 0.5$ & $6.73 \pm 0.51$ & $1.85 \pm 0.03$ & - & - \\
\hline $\begin{array}{l}\text { Standard Ranitidine } \\
10 \mathrm{mg} / \mathrm{kg}\end{array}$ & $11.25 \pm 0.96$ & $23 \pm 0.82$ & $4.85 \pm 0.31$ & $4.37 \pm 0.24$ & $80.5 \pm 1.0$ & $80.5^{*}$ \\
\hline BOME $20.50 \mathrm{mg} / \mathrm{kg}$ & $11.75 \pm 0.5$ & $34 \pm 0.82$ & $4.55 \pm 0.21$ & $4.39 \pm 0.36$ & $74.25 \pm 0.55$ & $73.25^{*}$ \\
\hline
\end{tabular}

Values are expressed as mean $\pm \mathrm{SD}(\mathrm{n}=4)$; At $95 \%$ confidence interval $* \mathrm{p}<0.05$ were considered significant. BOME - B. oleracea methanolic extract 


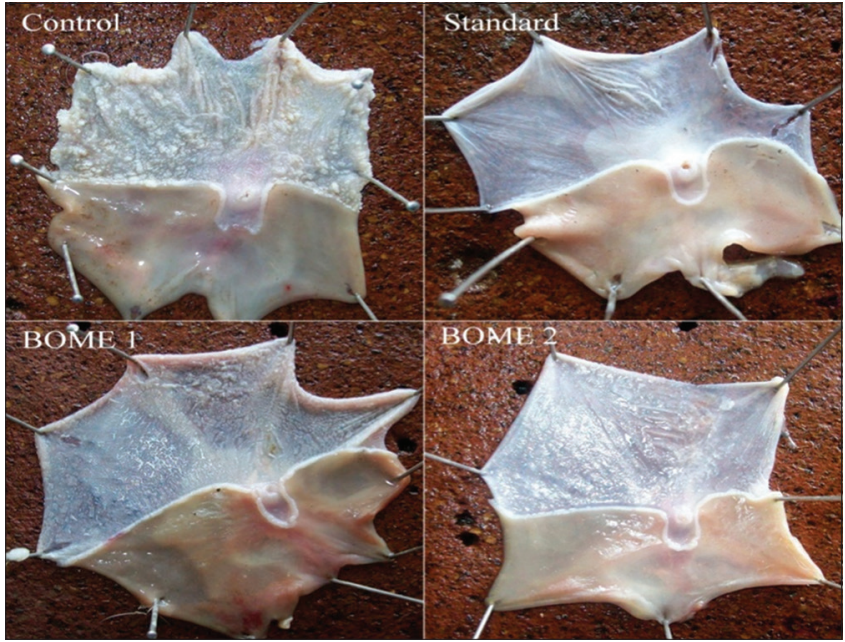

Plate 1: Antiulcer activity by pyloric ligation method

key pathogenic factors for gastric ulcer induction [27]. In this study, pyloric ligation model caused a significant increase in gastric juice discharge, total acidity, and marked peptic ulcer lesions. In consonance with the report of [28], gastric ulcer lesion recorded in this study may be due to inhibition of PG synthesis that induced gastric acidity, and consequently, stomach susceptibility to mucosal injury. Therapeutic agents of peptic ulcers generally depend on the inhibition of gastric acid secretion by histamine $\mathrm{H} 2$ antagonists [29,30]. Similar to our results, the most active subfraction of Buchanania lanzan ethyl acetate (BLE) exerted a significant dose-dependent decrease in the ulcerative lesion index produced by APL ulcer model in rats as compared to the standard drugs omeprazole (30 mg/kg, b.w orally) and ranitidine ( $32 \mathrm{mg} / \mathrm{kg}$, b.w orally), respectively. The reduction in gastric fluid volume, total acidity, and an increase in the $\mathrm{pH}$ of the gastric fluid in APL treated rats proved the antisecretory activity of most active subfraction of BLE. The oral administration of most active subfraction (F4) of ethyl acetate fraction of methanolic leaf extract of B. lanzan Spreng produced significant antiulcer activity [31]. The antiulcer activity was investigated in M. pudica. Among the methanolic, chloroform and diethyl ether extracts, methanolic extract showed significant activity [21] which coincides with our results. $200 \mathrm{mg} / \mathrm{kg}$ methanolic extract was significant in the range $\mathrm{p}<0.001$.

\section{SUMMARY AND CONCLUSION}

The methanolic extract of $B$. oleracea var. capitata rubra in the dose $0.50 \mathrm{mg} / \mathrm{kg}$ produced significant $(\mathrm{p}<0.05)$ antiulcer activity. On the basis of the present results, it can be finally concluded that $B$. oleracea var. capitata rubra can be used as an effective herbal medicine for ulcer conditions. Hence, further research is required to isolate individual components, characterize the active phytochemical constituents responsible for the activity and formulation of a potent antiulcer drug from B. oleracea var. capitata rubra.

\section{ACKNOWLEDGMENT}

The authors are thankful to the Principal and the Management of V.V. Vanniaperumal College for Women, Virudhunagar, Tamil Nadu, India, and Sankaralingam Bhuvaneswari College of Pharmacy, Anaikuttam, Sivakasi, Tamil Nadu, India for providing necessary facilities to carry out this research work.

\section{REFERENCES}

1. Akhtar MS, Khtar AH, Khan MA. Antiulcerogenic effects of Ocimum basilicum of extracts, volatile oils and flavonoid glycosides in albino rats. Int J Pharmacogn 1992;30:97-8.

2. Hassimotto NM, Genovese MI, Lajolo FM. Antioxidant activity of dietary fruits, vegetables, and commercial frozen fruit pulps. J Agric Food Chem 2005;53:2928-35.
3. Arapitsas P, Turner C. Pressurized solvent extraction and monolithic column-HPLC/DAD analysis of anthocyanins in red cabbage. Talanta 2008; $74: 1218-23$.

4. Barbara P, Grażyna HC, Emilia M, Sylwester C. Stability and antioxidative properties of acylated anthocyanins in three cultivars of red cabbage (Brassica oleracea L. var. capitata L. f. rubra). J Sci Food Agric 2009;89:1154-8.

5. Kyung KH, Fleming HP. S-methyl-L-cysteine sulfoxide as the precursor of methyl methanethiolsulfinate, the principal antibacterial compound in cabbage. J Food Sci 1994;59:350-5.

6. Hu SH, Wang JC, Kung HF, Wang JT, Lee WL, Yang YH. Antimicrobial effect of extracts of Cruciferous vegetables. Kaohsiung J Med Sci 2004;20:591-9.

7. Ayaz FA, Hayırloglu. Phenolic acid contents of kale (Brassica oleraceae L. var. Acephala DC.) extracts and their antioxidant and antibacterial activities. Food Chem 2008;107:19-25.

8. Zhou K, Yu L. Total phenolic contents and antioxidant properties of commonly consumed vegetables grown in Colorado. LWT - Food Sci Technol 2006;39:1155-62.

9. Andarwulan N, Batari R, Sandrasari DA, Bolling B, Wijaya, H. Flavonoid content and antioxidant activity of vegetables from Indonesia. Food Chem 2010;121:1231-5.

10. Isabelle M, Lee BL, Lim MT, Koh WP, Huang D, Ong CN. Antioxidant activity and profiles of common vegetables in Singapore. Food Chem 2010;120:993-1003.

11. Samec D, Piljac-Zegarac J, Bogovi M. Antioxidant potency of white (Brassica oleracea L. var. capitata) and Chinese (Brassica rapa L. var. Pekinensis (Lour.)) cabbage: The influence of development stage, cultivar choice and seed selection. Sci Hortic 2011;128:78-83.

12. Ayshwarya M, Sudha Rameshwari. K. Qualitative and quantitative analysis of phytochemicals in Brassica oleracea var capitata rubra. Int J Multidisciplinary Res 2015;4 (6):120-36.

13. Ayshwarya M, Sudha Rameshwari K. Antimicrobial activity of the plant extracts of Brassica oleracea var. Capitata rubra. J Int Acad Res Multidiscip 2015a;3(10):149-56.

14. Ayshwarya M, Sudha Rameshwari K. Assessment of antioxidant activity in Brassica oleracea var. capitata rubra. J Med Sci Clin Res 2015b;3(12):8536-41.

15. Rameshwari KS, Ayshwarya M. Anti-inflammatory and antipyretic activity of methanol extracts Brassica oleracea var capitata rubra in Wister rats. Int J Curr Res 2016;8(03):27299-302.

16. Kulkarni SS. Practical Pharmacology and Clinical Pharmacy. Delhi: Vallash Publication; 2008

17. Gordan MH. The mechanism of the anti-oxidant action in vitro. In: Hudson BJ, editor. Food Antioxidants. London: Elsevier; 1990. p. 1-18.

18. Szabo S, Szienji S. 'Cytoprotection' in gastrointestinal pharmacology. Trends Pharma Sci 1987;8:149-154.

19. Aly A, Scand. J. Prostaglandins in clinical treatment of gastro duodenal mucosal lesions: A review. Gastroenterol 1987;137:43-9.

20. de Carvalho CA, Fernandes KM, Matta SL, Silva MB, Oliveira LL, Fonseca CC. Evaluation of antiulcerogenic activity of aqueous extract of Brassica oleracea var. Capitata (CABBAGE) on wistar rat gastric ulceration. Arq Gastroenterol 2011;48(4): 276-82

21. Vinothapooshan G, Sundar K. Anti-ulcer activity of Mimosa pudica leaves against gastric ulcer in rats. Res J Pharm Biol Chem Sci 2010;1(4):606-14

22. Cheney G. Vitamin $U$ therapy of peptic ulcer. Calif Med 1952;77 (4):248-52.

23. Gonzalez FG, Di Stasi LC. Anti-ulcerogenic and analgesic activities of the leaves of Wilbrandia ebracteata in mice. Phytomedicine 2002;9 (2):125-34

24. Tiwari DK, Tripathi RK, Jena J. Evaluation of antiulcer and antianxiety activity of phanamixispolystachya stems bark extract on rats. Int J Pharm Pharm Sci 2013;5:148-51.

25. Harvey AL, Edrada-Ebel R, Quinn RJ. The re-emergence of natural products for drug discovery in the genomics era. Nat Rev Drug Discov 2015;14:111-29.

26. Sayed DA, Fahmy SR, Soliman AM, Hussein NS. Antiulcerogenic efficacy of an ethanolic extract of Vitis vinifera leaves in rats. Int $\mathrm{J}$ Pharm Pharm Sci 2016;8(9):163-72.

27. Fahmy SR, Amer MA, Al-killidar MH. Ameliorative effect of the sea cucumber Holothuriaarenicola extracts against gastric ulcer in rats. J Basic Appl Zool 2015;72:16-25.

28. Nagar H, Tiwari P, Jain DK, Chandel HS. Evaluation of the antiulcer activity of stem bark extract of Aphanmixis polystachya in experimental rats. Indian J Pharm Educ Res 2012;46:222-7.

29. Bighetti AE, Antonio MA, Kohn LK, Rehder VL, Foglio MA, 
Possenti A, et al. The Antiulcerogenic activity of a crude hydroalcoholic extract and coumarin isolated from Mikanialaevigata Schultz bip. Phytomedicine 2005;12:72-7.

30. John-Africa BL, Idris-Usman MS, Adzu B, Gamaniel KS. Protective effects of the aqueous extract of Nymphaea lotus L. (Nymphaeaceae) against ethanol-induced gastric ulcers. Int $\mathrm{J}$ Biol Chem Sci 2012;6:1917-25

31. Rai U, Pattnaik AK, Singh S. Antiulcer activity of the most active subfraction of methanolic leaf extract of Buchanania lanzan spreng. Int J Pharm Pharm Sci 2016;8(9):93-101. 